\title{
Effect of Yb Substitution in Bi-2212 Ceramics Prepared by Laser Floating
} Zone Technique

B. Ozkurt ${ }^{1}$, B. Ozcelik², M. A. Madre ${ }^{3}$, A. Sotelo ${ }^{3}$, J. C. Diez ${ }^{3}$

${ }^{1}$ Department of Energy Systems Engineering, Faculty of Tarsus Technology, University of Mersin, Mersin, Turkey

2 Department of Physics, Faculty of Sciences and Letters, Cukurova University, 01330 Adana, Turkey

${ }^{3}$ ICMA (CSIC-Universidad de Zaragoza), Marı'a de Luna, 3, 50018 Zaragoza, Spain

\begin{abstract}
In the present work, the influence of $\mathrm{Yb}$ substitution for $\mathrm{Bi}$ on the structrual, electrical and magnetic properties of textured Bi-2212 ceramics has been investigated. X-ray diffraction studies indicated that the major peaks correspond to the $\mathrm{Bi}-2212$ phase. The SEM images clearly show that there is an increase in the number of secondary phases with raising $\mathrm{Yb}$ content while all samples maintain similar grain morphology. Magnetic analysis of all samples has been done by magnetic hysteresis measurements, indicating that an enhancement in the $\mathrm{M}-\mathrm{H}$ loops is obtained by a low $\mathrm{Yb}$ doping. The critical current density of samples was calculated from the M-H curves by using Bean's critical state model, indicating that samples with $0.05 \mathrm{Yb}$ substitution possess the highest $\mathrm{J}_{\mathrm{c}}$ values.
\end{abstract}




\section{Introduction}

High-temperature phases in BSCCO ceramics are very sensitive to the fabrication methods due to their anisotropic character. Solid-state reaction method is one of the simplest and most harmless methods for preparing of ceramic superconductors involving mixing, calcination and sintering. Also, many works show that high $J_{c}$ values can be easily obtained by optimal adjustments in parameters such as annealing time, postannealing temperature and pelletization pressure [1-4].

However, the most important disadvantages of the solid state method are causing low homogeneity and high amount of secondary phases due to their low reactivity, together with the production of randomly oriented superconducting grains. In this scenario, synthesis methods play an important role on the production of higher homogeneity materials due to the fact that precursors are composed by smaller grains with higher reactivity $[5,6]$. On the other hand, it is well-known that a good grain orientation is necessary to obtain high electrical current capabilities in these materials [7]. Among other successful techniques to produce well oriented grains, the laser texturing ensures a high degree of texture at relatively high rates [7-11]. Besides these useful methods used in the preparation of ceramic superconductors such as the laser floating zone (LFZ) [12] and the electrically assisted laser floating zone (EALFZ) techniques [13], cation doping [14-27] or metallic additions [28-30] can also ensure the important improvements in the basic properties of the BSCCO system.

It can be expected that dopant elements can substitute elements in the subunit cell of $\mathrm{Bi}-2223$ or $\mathrm{Bi}-2212$ phases in BSCCO system when the ionic radius of dopant elements are close in size to that of the elements in the crystal unit. Moreover, foreign dopant elements can also incorporate rather than substituting sites in the high temperature phases of BSCCO to be more energetically stable. These interactions can be seen in many cases because of important differences in the ionic radius in the BSCCO system. If dopant elements can create the effective pinning centers to fix vortices or improve connectivity between grains, it is possible to reach high $\mathrm{J}_{\mathrm{c}}$ values in BSCCO ceramics.

Based in previously obtained results [31,32], the aim of the present work is to investigate the effect of $\mathrm{Yb}$ doping for $\mathrm{Bi}$ sites on basic properties of textured $\mathrm{Bi}$ - 
2212 ceramics using the LFZ method when the materials are prepared by a polymer solution route. The samples are characterized using X-ray powder diffraction (XRD), scanning electron microscopy (SEM), DC electrical resistivity and magnetic-hysteresis loop measurements.

\section{Experimental details}

$\mathrm{Bi}_{2-\mathrm{x}} \mathrm{Yb}_{\mathrm{x}} \mathrm{Sr}_{2} \mathrm{CaCu}_{2} \mathrm{O}_{\mathrm{y}}$ samples, with $\mathrm{x}=0.0,0.05,0.1$ and $0.25 \mathrm{Yb}$ additions, have been prepared by a polymer solution route from commercial $\mathrm{Bi}\left(\mathrm{CH}_{3} \mathrm{COO}\right)_{3}(\geq$ 99.99\%, Aldrich), $\mathrm{Sr}\left(\mathrm{CH}_{3} \mathrm{COO}\right)_{2} \cdot 1 / 2 \mathrm{H}_{2} \mathrm{O}$ (99\%, Panreac), $\mathrm{Ca}\left(\mathrm{CH}_{3} \mathrm{COO}\right)_{2} \cdot \mathrm{H}_{2} \mathrm{O}$ (98\%, Alfa Aesar), $\mathrm{Cu}\left(\mathrm{CH}_{3} \mathrm{COO}\right)_{2} \cdot \mathrm{H}_{2} \mathrm{O}\left(98 \%\right.$, Panreac), and $\mathrm{Yb}\left(\mathrm{CH}_{3} \mathrm{COO}\right) \cdot \mathrm{H}_{2} \mathrm{O}$ $(99.9 \%$, Alfa Aesar) powders. They were weighed in the appropriate proportions, and dissolved in a mixture of glacial acetic acid and water. To the resulting clear blue solution, polyethyleneimine (PEI) (Aldrich, 50 wt.\% water) was added and the solution turns to deep blue immediately. The solution was then concentrated in a rotary evaporator and finally totally dried on a hot plate at about $100^{\circ} \mathrm{C}$, producing a deep blue thermoplastic paste. Further heating at about $300{ }^{\circ} \mathrm{C}$ decomposes the organic material with the release of $\mathrm{CO}_{2}$ and nitrogen oxides. The fine powder was then thermally treated at 750 and $800{ }^{\circ} \mathrm{C}$ for $12 \mathrm{~h}$ with an intermediate milling in order to decompose the alkaline-earth carbonates. The final powders were isostatically pressed in form of cylinders at about $200 \mathrm{MPa}$. These green ceramic cylinders were grown in a LFZ system using a growth rate of $15 \mathrm{~mm} / \mathrm{h}$ and a relative rotation of $18 \mathrm{rpm}$ between the seed and feed. Details on the material preparation can be found in previous works [33].

Finally, annealing process in order to reach a large amount of pure 2212BSCCO was performed in two steps: $60 \mathrm{~h}$ at $860^{\circ} \mathrm{C}$, followed by $12 \mathrm{~h}$ at $800^{\circ} \mathrm{C}$ and, finally, quench in air to room temperature.

Samples with $\mathrm{x}=0.0,0.05,0.1$ and $0.25 \mathrm{Yb}$ contents will hereafter be named $A$, $B, C$, and $D$, respectively.

Resistivity and magnetic measurements were carried out using Cryogenic Limited PPMS (from 5 to $300 \mathrm{~K}$ ) which can reach the cryogenic temperatures about to $2 \mathrm{~K}$ in a closed-loop He system. X-ray powder diffraction analyses to determine the phases present in the samples were performed in a Rigaku Ultima IV X-Ray Diffractometer with a constant scan rate (2 degree/minute) in 
the range $2 \theta=3-60^{\circ}$. Lattice parameters have been automatically calculated by the PDXL software version 1.6.0.1 with the ICDD version 6.0 database. Microstructural characterization was made on the polished longitudinal crosssections of the samples, after the annealing process, in a scanning electron microscope (SEM, JEOL JSM 6400) equipped with an energy dispersive spectroscopy (EDX) system.

\section{Results and discussion}

\subsection{XRD characterization}

Fig. 1 shows the XRD patterns of all samples. From these patterns, it has been observed that major peaks correspond to $\mathrm{Bi}-2212$ phase while some minor ones observed at $2 \theta \cong 20.48^{\circ}, 36.76^{\circ}$ and $57.08^{\circ}$ indicate the presence of $\mathrm{Bi}_{2} \mathrm{CaO}_{4}$ and $\mathrm{Bi}_{4} \mathrm{Sr}_{4} \mathrm{CaCu}_{3} \mathrm{O}_{14}$ secondary phases in small proportions. It is worth to highlight that small amount of non-superconducting phases cannot significantly affect superconducting critical transition temperatures $\left(T_{c}\right)$ while they can lead to high $J_{c}$ values with the formation of effective pinning centers.

On the other hand, the lattice parameters summarized in Table 1 show that all samples have tetragonal crystal structure. The lattice parameter $\mathrm{c}$ in BSCCO superconductors can easily change due to the fact that the coupling between $\mathrm{BiO}$ layers in the crystallographic unit cell of BSCCO is weak. However, all samples have nearly similar values in their c parameter even if it linearly decreases with increasing $\mathrm{Yb}$ content, implying that there is no significant phase change in these samples.

\subsection{SEM analysis}

Fig. 2 shows SEM micrographs including longitudinal polished parts of samples. From these micrographs, it is clear that the grey conrast in all samples is the major one which has been associated by EDX to the Bi-2212 phase. Note that the different contrasts found in the micrographs indicate the different phases which can be easily analyzed by EDX analysis [34]. However, the amount of dark grey and white contrasts increase with increasing $\mathrm{Yb}$ content, implying that the increase in $\mathrm{Yb}$ content produces non-superconducting phases in the bulk samples. This effect can also cause both the degradation of the crystal plane 
alignment and the grain connectivity. Sample D with $0.25 \mathrm{Yb}$ content have the major amount of secondary phases, which can lead to the degradation of its superconducting properties.

\subsection{Electrical measurements}

Fig. 3 shows the temperature dependence of the electrical resistivity for all samples. It is obvious from Table I that all samples have high $T_{c}$ (onset) and $T_{c}$ (offset) transition temperatures, indicating that they have adequate oxygen content and well aligned grains aimed by LFZ method. Despite the variation of the resistivity at room temperature, its evolution is linear and decreases between room temperature and $\mathrm{T}_{\mathrm{c}}$ (onset), typical behavior for materials with $\mathrm{Bi}$ 2212 phase as the major one. Sample D with $0.25 \mathrm{Yb}$ content has the highest resistivity at room temperature due to the higher content of secondary phases. On the other hand, $T_{c}$ (offset) values linearly decrease when $Y b$ content is increased. These decreases in the offset critical transition temperatures with increasing $\mathrm{Yb}$ content can imply negative effects in the intergrain connectivity while the decreased $T_{c}$ (onset) values reflect the decrease in the Bi-2212 phase formation.

\subsection{Magnetic properties}

The magnetic-hysteresis cycles, between applied fields of $\pm 2 \mathrm{~T}$, for all the samples at 10 and $25 \mathrm{~K}$, are presented in Figs. 4 and 5, respectively. It is well known that the magnetic hysteresis curves of superconductors can show different behavior depending on factors such as the number and kind of secondary phases in the sample, the presence of pores and different grain connectivity. While all samples have the basic diamagnetic behavior of the high$T_{C}$ superconductors, undoped sample $A$ has higher magnetization values at low applied fields. However, sample B with $0.05 \mathrm{Yb}$ content shows a larger hysteresis loop compared with all the other samples at high magnetic fields.

On the other hand, it is clearly seen from Fig. 5 that samples maintain their M-H behavior even if $\mathrm{M}-\mathrm{H}$ measurements are taken at $25 \mathrm{~K}$, indicating that the number of effective pinning centers in sample $B$ is higher than other samples.

The $J_{C}$ values of the samples were calculated from the hysteresis loops at $10 \mathrm{~K}$, using the Bean's model [35]: 


$$
\mathrm{J}_{\mathrm{c}}=30 \frac{\Delta M}{d}
$$

where $\mathrm{J}_{\mathrm{C}}$ is the magnetization current density in ampéres per square centimeter. $\Delta M=M_{+}-M_{-}$is measured in electromagnetic units per cubic centimeter, and $\mathrm{d}$ is the thickness of sample.

Fig. 6 shows the calculated critical current densities for all the samples, as a function of the applied field, at $10 \mathrm{~K}$. The highest $J_{c}$ values are obtained for sample $B$ at higher applied fields than 0.6 T. SEM investigation of samples showed that grain alignment negatively change with the increasing nonsuperconducting phases, indicating that enhancements in $J_{c}$ for sample $B$ can be explained by the formation of new effective pinning centers. As a consequence, the highest $\mathrm{J}_{\mathrm{c}}$ value obtained at $\mathrm{H}=0.6 \mathrm{~T}$ is around $28.1 \times 10^{4}$ $\mathrm{A} / \mathrm{cm}^{2}$ for sample $\mathrm{B}$.

\section{CONCLUSIONS}

From the XRD studies, the automatically calculated c-axis parameters have been found to decrease with the increased $\mathrm{Yb}$ content. Moreover, no Yb-based secondary phase has been identified, indicating that $\mathrm{Yb}$ can be incorporated in the Bi-2212 phase. Electrical resistivity measurements showed that both $\mathrm{T}_{\mathrm{c}}$ (onset) and $T_{c}$ (offset) values gradually decrease with the increasing $Y b$ amount. However, the best results in both $\mathrm{M}-\mathrm{H}$ loops and $\mathrm{J}_{\mathrm{c}}$ values at high applied fields, have been obtained for samples $\mathrm{B}$ with $0.05 \mathrm{Yb}$ content.

\section{Acknowledgements}

The authors wish to thank the Gobierno de Aragón and Fondo Social Europeo (Grupos de Investigacion Consolidados T12 and T87) and MINECO-FEDER (MAT2013-46505-C3-1-R) for financial support.

SEM micrographs of all samples have been taken in Zaragoza University in Spain as XRD measurements have been made in the MEITAM Central Laboratory at Mersin University. Also, R-T and M-H measurements in this study have been made in the METU Central Laboratory in Middle East Technical University in Ankara in Turkey. 
On the other hand, we wish to thank PhD. M. Serkan YALÇIN in the MEITAM Central Laboratory and Dr. Ibrahim ÇAM in the METU Central Laboratory for their experimental support and very meticulous work.

\section{References}

1. B. Özkurt, M.A. Madre, A. Sotelo, J.C. Diez, Physica B 426,85 (2013)

2. B. Özkurt, M.A. Madre, A. Sotelo, J.C. Diez, J. Supercond. Nov. Magn. 26, 3247 (2013)

3. M. Ersin Aytekin, B. Özkurt, İ. Sugözü, J. Mater. Sci. 26, 1799 (2015)

4. B. Ozcelik, B. Ozkurt, M. E. Yakinci, A. Sotelo, M. A. Madre, J. Supercond. Nov. Magn. 26, 873 (2013)

5. A. Sotelo, P. Majewski, H. S. Park, F. Aldinger, Physica C 272, 115 (1996)

6. A. Sotelo, G. F. de la Fuente, F. Lera, D. Beltran, F. Sapina, R. Ibanez, A. Beltran, M. R. Bermejo, Chem. Mater. 5, 851 (1993)

7. Y. Huang, G. F. de la Fuente, A. Sotelo, A. Badia, F. Lera, R. Navarro, C. Rillo, R. Ibanez, D. Beltran, F. Sapina, A. Beltran, Physica C 185, 2401 (1991)

8. R.S. Feigelson, D. Gazit, D.K. Fork, T.H. Geballe, Science 240, 1672 (1988)

9. A. Sotelo, M. A. Madre, J. C. Diez, Sh. Rasekh, L. A. Angurel, E. Martinez. Supercond. Sci. Technol. 22, 034012 (2009)

10. M. Mora, A. Sotelo, H. Amaveda, M. A. Madre, J. C. Diez, F. Capel, J.M. Lopez-Cepero, J. Eur. Ceram. Soc. 27, 3959 (2007)

11. G. F. de la Fuente, M. T. Ruiz, A. Sotelo, A. Larrea, R. Navarro. Mater. Sci. Eng. A 173, 201 (1993)

12. V. Lennikov, B. Ozkurt, L. A. Angurel, A. Sotelo, B. Ozcelik, G. F. de la Fuente, J. Supercond. Nov. Magn. 26, 947 (2013)

13. B. Ozkurt, M. A. Madre, A. Sotelo, M. E. Yakinci, B. Ozcelik, J. C. Diez, J. Supercond. Nov. Magn. 26, 1093 (2013)

14. F.M. Costa, S. Rasekh, N.M. Ferreira, A. Sotelo, J.C. Diez, M.A. Madre, J. Supercond. Nov. Magn. 26, 943 (2013)

15. H. Sözeri, N. Ghazanfari, H. Özkan, A. Kılıç, Supercond. Sci. Technol. 20, 522 (2007)

16. L. Jiang, Y. Sun, X. Wan, K. Wang, G. Xu, X. Chen, K. Ruan, J. Du, Physica C 300, 61 (1998) 
17. M. Zargar Shoushtari, S.E. Mousavi Ghahfarokhi, J. Supercond. Nov. Magn. 24, 1505 (2011)

18. A.I. Abou-Aly, M.M.H. Abdel Gawad, R. Awad, I. G-Eldeen, J. Supercond. Nov. Magn. 24, 2077 (2011)

19. S. Şakiroğlu, K. Kocabaş, J. Supercond. Nov. Magn. 24, 1321 (2011)

20. S.M. Khalil, J. Phys. Chem. Solids 62, 457 (2001)

21. M.A. Madre, H. Amaveda, M. Mora, A. Sotelo, L.A. Angurel, J.C. Diez, Bol. Soc. Esp. Ceram. 47, 148 (2008)

22. Y.L. Chen, R. Stevens, J. Am. Ceram. Soc. 75, 1150 (1992)

23. R. Ramesh, S. Green, C. Jiang, Y. Mei, M. Rudee, H. Luo, G. Thomas, Phys. Rev. B, Condens. Matter. 38, 7070 (1988)

24. B. Ozkurt, J. Alloy. Compd. 579, 132 (2013)

25. B. Ozkurt, J. Mater. Sci. 24, 2426 (2013)

26. C. Kaya, B. Ozcelik, B. Ozkurt, A. Sotelo, M. A. Madre, J. Mater. Sci.: Mater. Electron. 24, 1580 (2013)

27. B. Ozkurt, M. A. Madre, A. Sotelo, J. C. Diez, J. Mater. Sci.: Mater. Electron. 24, $1158(2013)$

28. A. Ozaslan, B. Ozcelik, B. Ozkurt, A. Sotelo, M. A. Madre, J. Supercond. Nov. Magn. 27, 53 (2014)

29. A. Sotelo, M. Mora, M.A. Madre, J.C. Diez, L.A. Angurel, G.F. de la Fuente, J. Eur. Ceram. Soc. 25, 2947 (2005)

30. M. Mora, A. Sotelo, H. Amaveda, M.A. Madre, J.C. Diez, L.A. Angurel, G.F. de la Fuente, Bol. Soc. Esp. Ceram. V. 44, 199 (2005)

31. B. Ozkurt, M. A. Madre, A. Sotelo, J. C. Diez, J. Mater. Sci.: Mater. Electron. 24, 3344 (2013)

32. A. Sotelo, H. Szillat, P. Majewski, F. Aldinger, Supercond. Sci. Technol. 10, 717 (1997)

33. H. Gundogmus, B. Ozcelik, A. Sotelo, M. A. Madre, J. Mater. Sci.: Mater. Electron. 24, 2568 (2013)

34. H.Gündoğmuş, B. Özçelik, B. Özkurt, A. Sotelo, M. A. Madre, J. Supercond. Nov. Magn. 26, 111 (2013)

35. B. Özkurt, M. A. Madre, A. Sotelo, M. Eyyüphan Yakıncı, B. Özçelik, J. Supercond. Nov. Magn. 25, 799 (2012)

36. C. P. Bean, Phys. Rev. Lett. 8, 250 (1962) 


\section{Figure captions}

Figure 1. $X R D$ patterns of the $A, B, C$, and $D$ samples. Bi-2212 diffraction peaks are identified by + .. The peaks of $\mathrm{Bi}_{2} \mathrm{CuO}_{4}$ and $\mathrm{Bi}_{4} \mathrm{Sr}_{4} \mathrm{CaCu}_{3} \mathrm{O}_{14}$ are shown by * and $\boldsymbol{\Lambda}$, respectively.

Figure 2. SEM micrographs of polished longitudinal sections of the $\mathrm{Yb}$ doped for Bi sites Bi-2212 textured materials after annealing: (a) sample A; (b) sample B; (c) sample C; and (d) sample D

Figure 3. Resistivity curves, as a function of temperature, for the different $\mathrm{Yb}$ substituted samples.

Figure 4. Magnetization hysteresis curves measured at $10 \mathrm{~K}$ for all samples

Figure 5. Magnetization hysteresis curves measured at $25 \mathrm{~K}$ for all samples

Figure 6. Calculated critical current densities for all samples at $10 \mathrm{~K}$, as a function of the external applied field. 
Table I. XRD and resistivity measurement results for the samples

\begin{tabular}{ccccccc}
\hline Samples & $\mathrm{a}(\AA)$ & $\mathrm{b}(\AA)$ & $\mathrm{c}(\AA)$ & $T_{C}^{\text {onset }}(\mathrm{K})$ & $T_{C}^{\text {offset }}(\mathrm{K})$ & $\begin{array}{c}\mathrm{R}(\mathrm{m} \Omega \mathrm{cm}) \\
\mathrm{at} 300 \mathrm{~K}\end{array}$ \\
\hline A & 3.829 & 3.829 & 30.952 & 101 & 95 & 0.44 \\
B & 3.824 & 3.824 & 30.868 & 100 & 89.2 & 1.73 \\
C & 3.834 & 3.834 & 30.853 & 95.6 & 84.8 & 2.15 \\
D & 3.831 & 3.831 & 30.709 & 95.3 & 84.5 & 2.63 \\
\hline
\end{tabular}


Figure 1

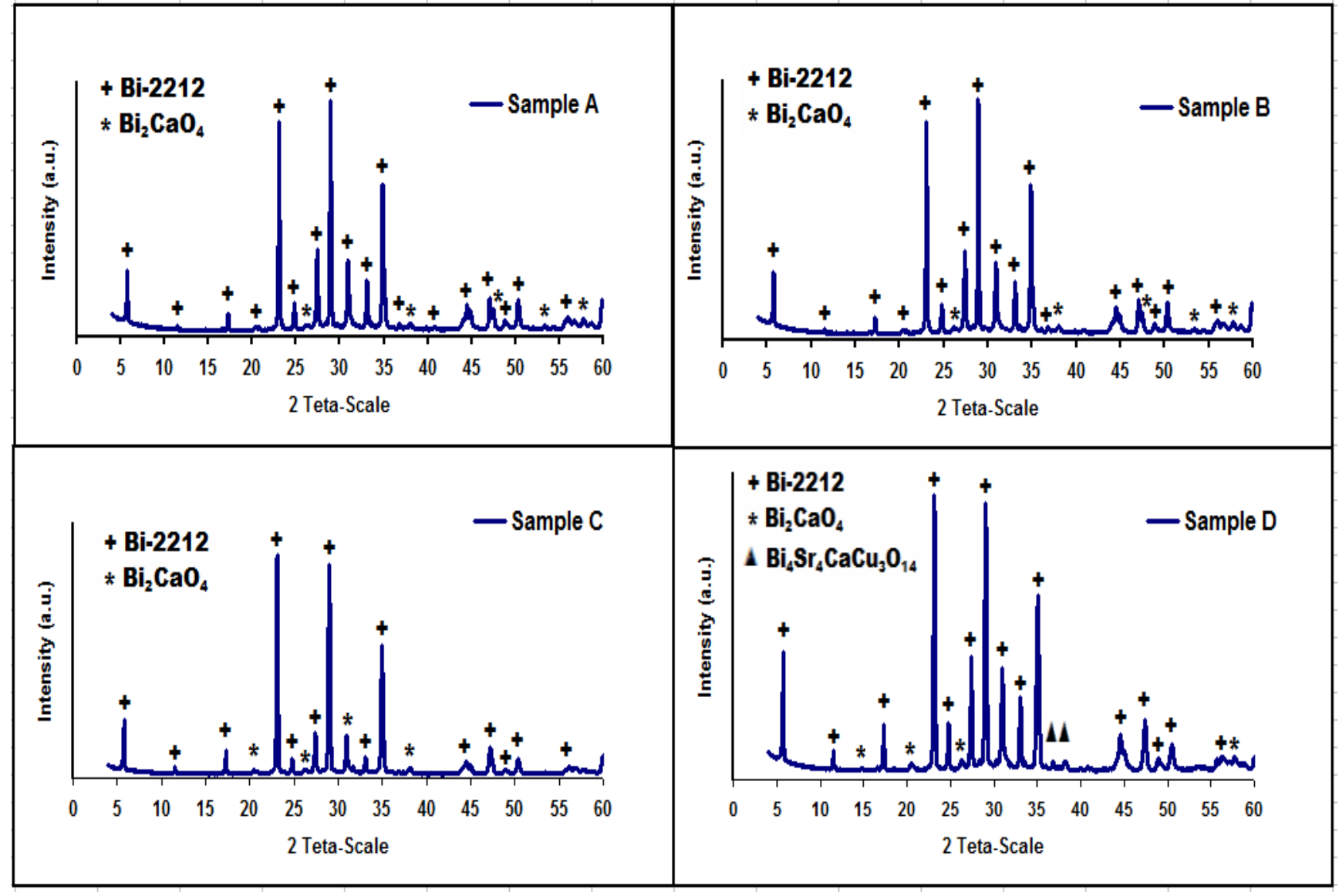


Figure 2

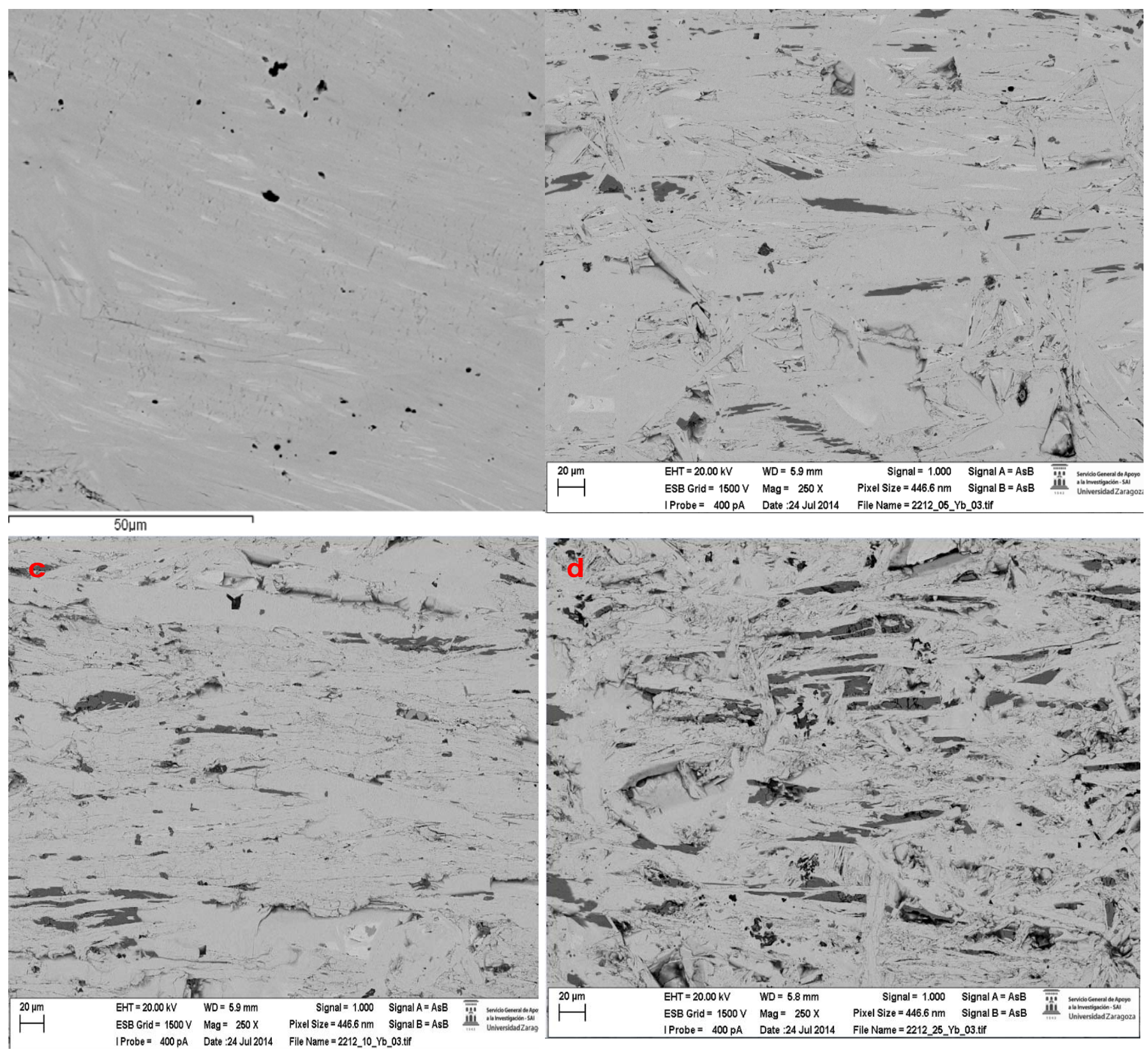


Figure 3

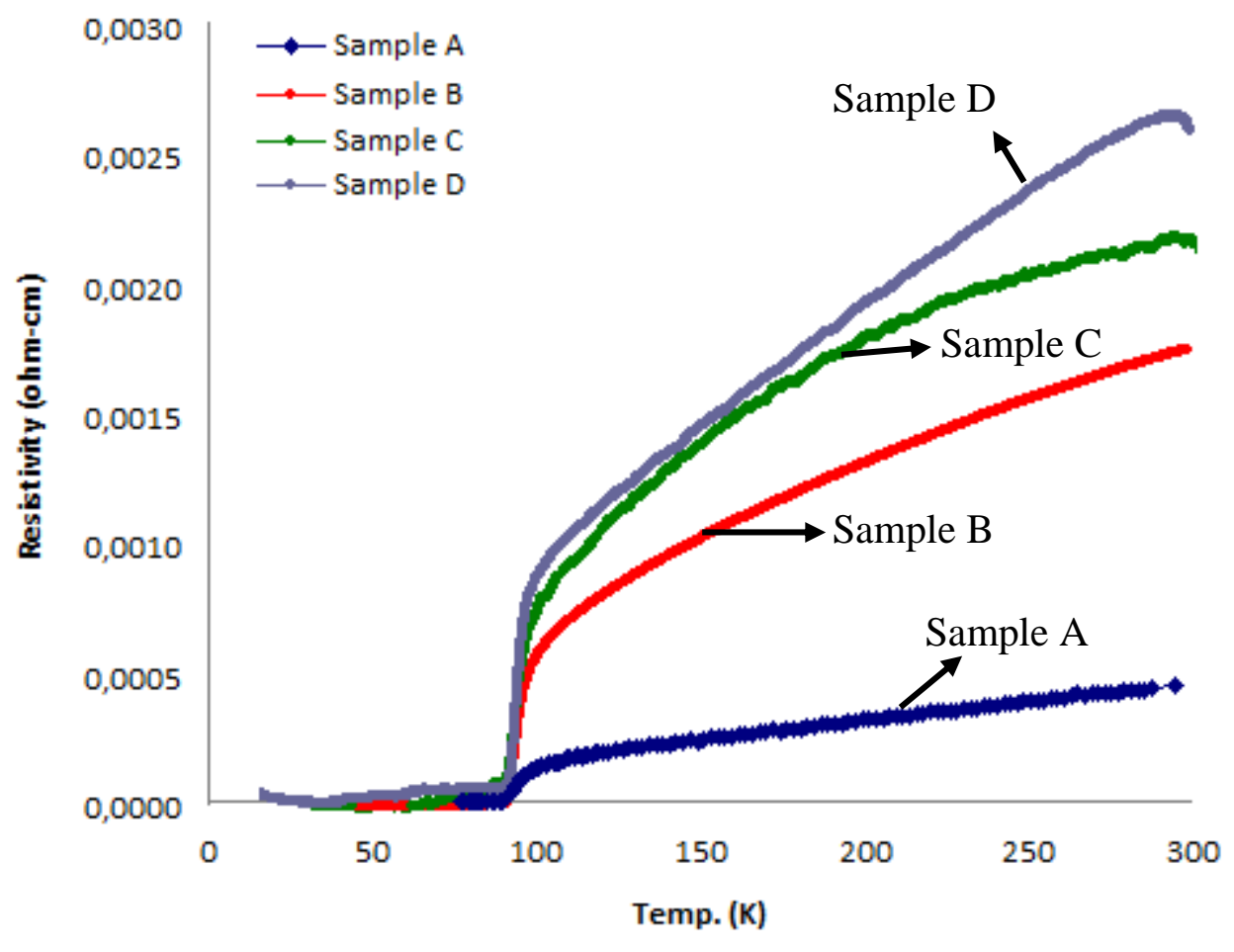


Figure 4

$$
\mathrm{T}=10 \mathrm{~K}
$$

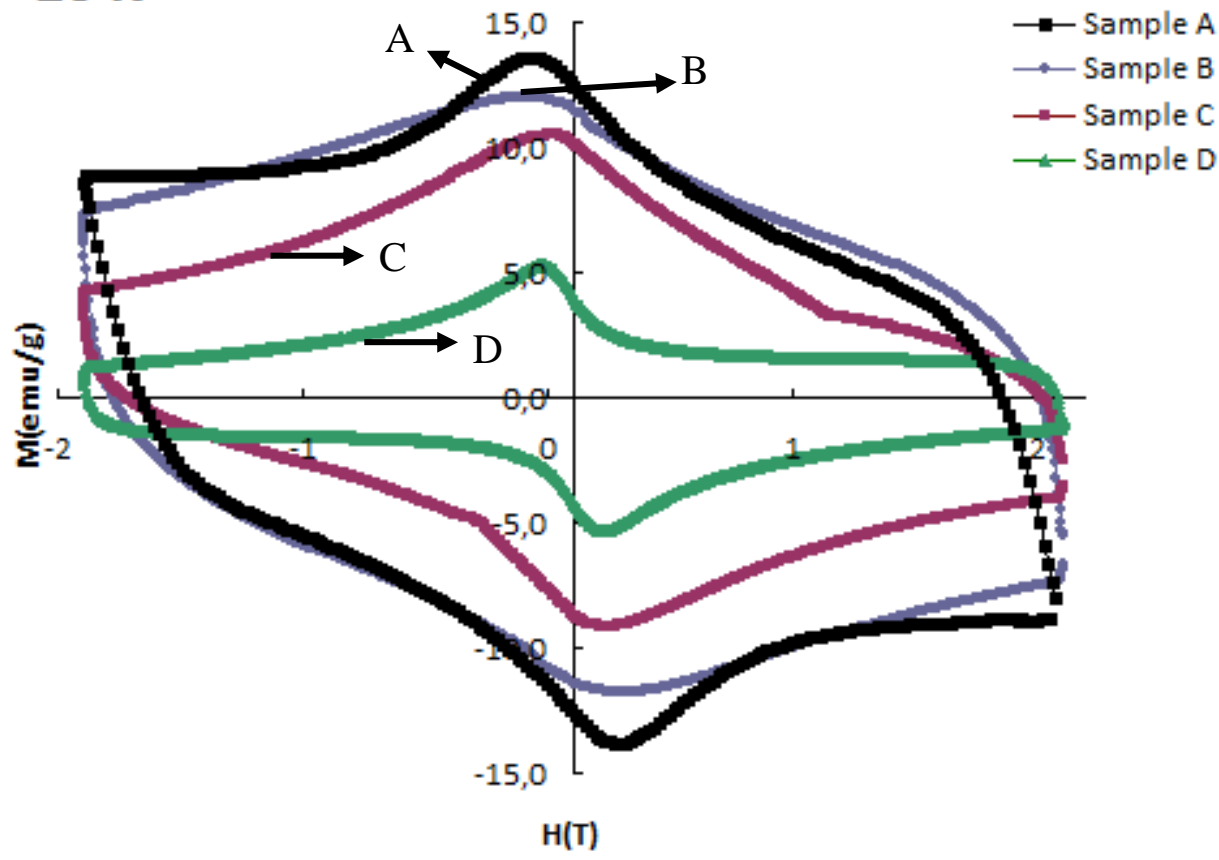


Figure 5

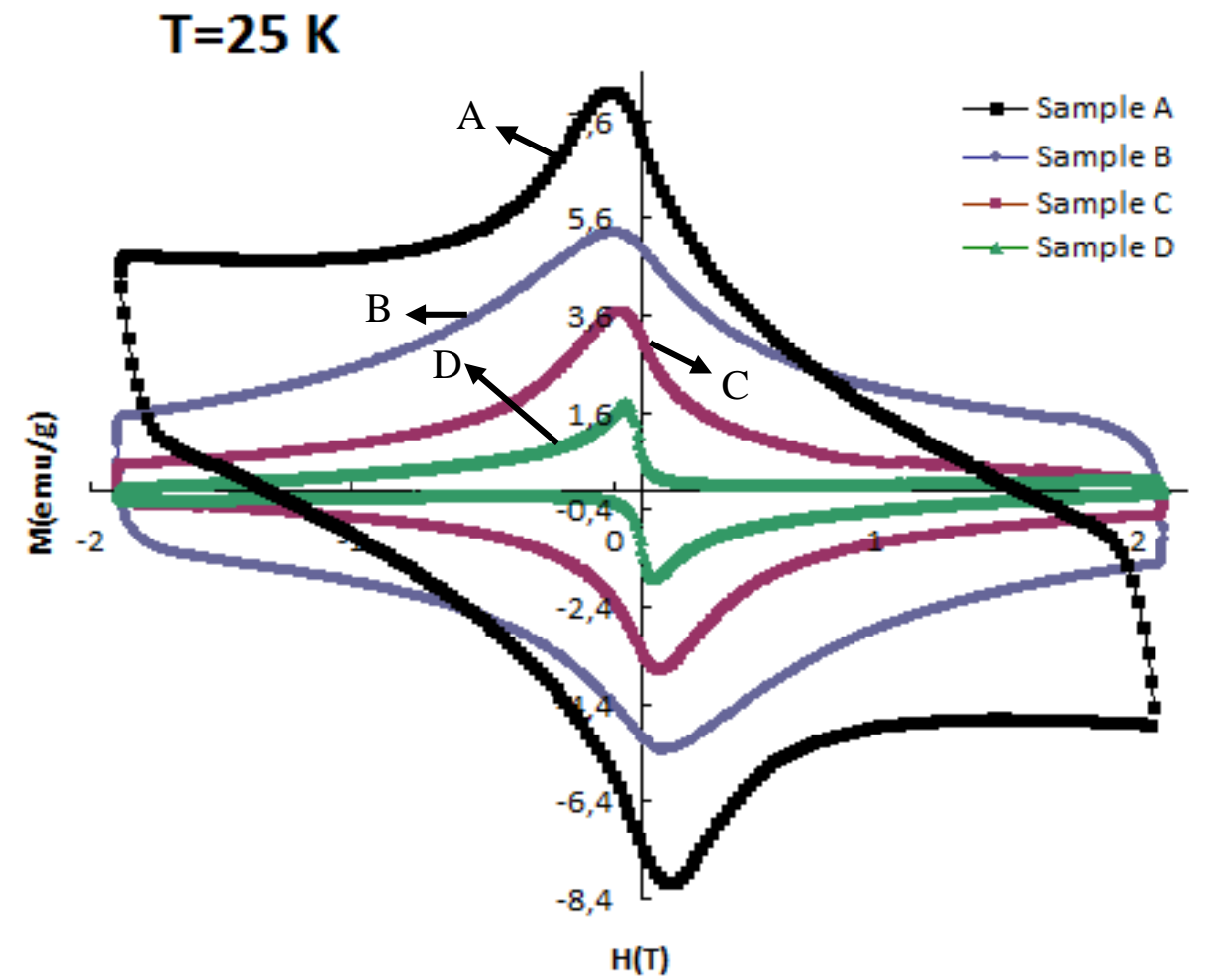


Figure 6

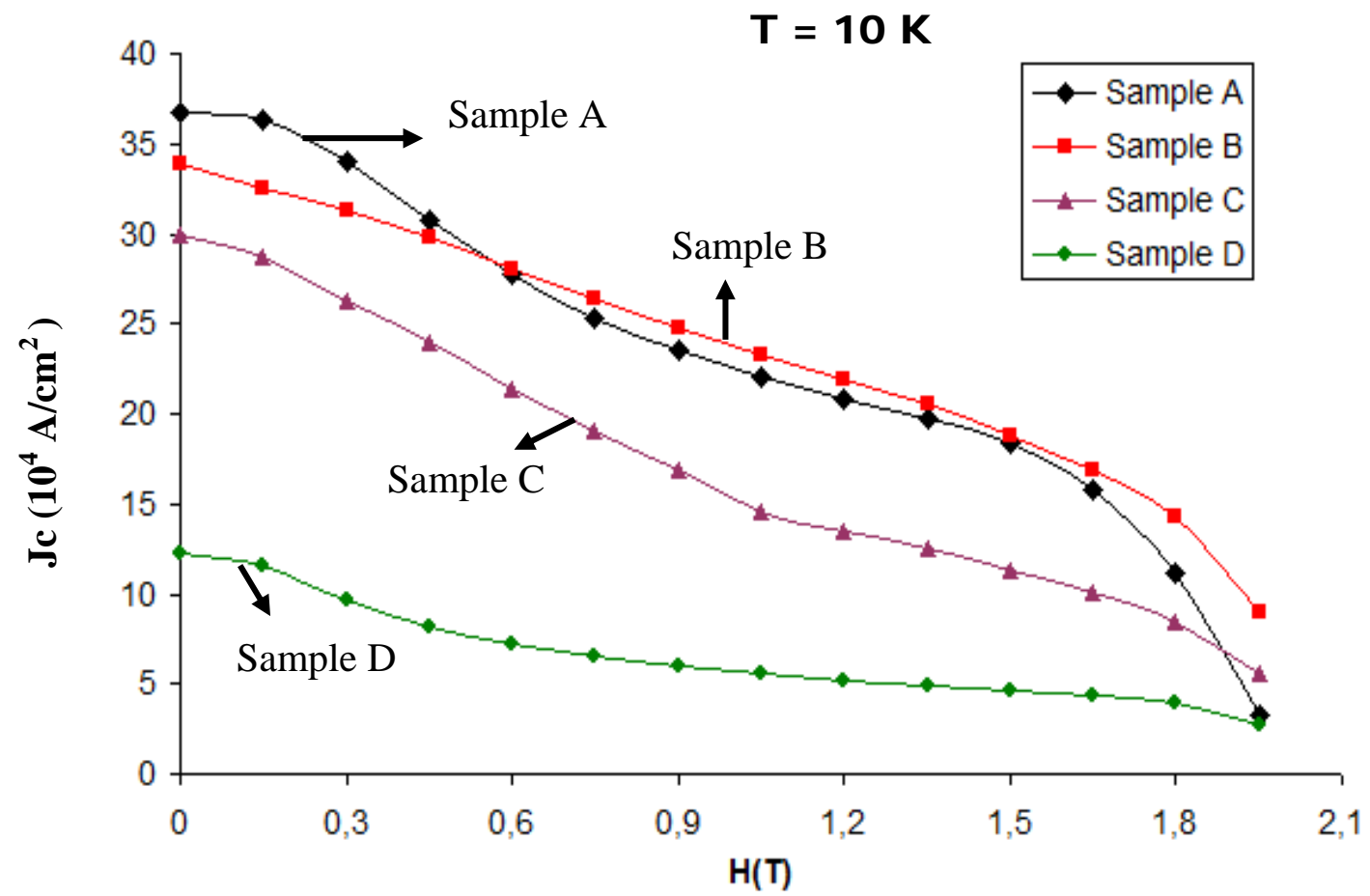

